\title{
Low birth weight: an observational study of maternal and neonatal factors in a rural tertiary care hospital, Telangana, India
}

\author{
Murty V. R. Nabhi*, Ramajyoti S., Vydehi B., Vasantha K., Vijayalakshmi Gillella
}

Department of Obstetrics and Gynaecology, Bhaskar Medical College, Moinabad, Hyderabad, Telangana, India

Received: 05 May 2021

Accepted: 08 June 2021

\section{*Correspondence:}

Dr. Murty V. R. Nabhi,

E-mail: nabhivrmurty@gmail.com

Copyright: (c) the author(s), publisher and licensee Medip Academy. This is an open-access article distributed under the terms of the Creative Commons Attribution Non-Commercial License, which permits unrestricted non-commercial use, distribution, and reproduction in any medium, provided the original work is properly cited.

\begin{abstract}
Background: Poor maternal health among Indian women is of global significance because India is home to $1 / 5^{\text {th }}$ of the world's births. $27 \%$ of these newborn babies in India are low birth weight (LBW), an important cause of high infant mortality. This study was conducted among puerperal women who delivered LBW babies in our hospital to know the various factors pertaining to socio-demographic, obstetric and anthropometric characteristics.

Methods: this observational study was conducted in the department of obstetrics and gynecology at Bhaskar medical college and hospital, Moinabad, Hyderabad from January 2016 to June 2017. The study sample were those who delivered LBW babies in our hospital and a set questionnaire was used to collect the relevant details.

Results: $75 \%$ of these mothers were in the age group of 20-25 years, $73.5 \%$ had more than 10 years of schooling. About $64 \%$ of these women had their $1^{\text {st }}$ antenatal visit in $1^{\text {st }}$ trimester of pregnancy and $54 \%$ had their $1^{\text {st }}$ ultrasound in $1^{\text {st }}$ trimester. 36 babies had NICU admission, either at our hospital or at a level III NICU facility, and all had good neonatal outcome.

Conclusions: The state must endeavor to make quality health free and easily accessible to pregnant women so that all can avail these services to better the maternal and neonatal outcomes. This will be helpful in improving the overall health of our population over the next few decades.
\end{abstract}

Keywords: LBW, Mothers, Socio-demographic, Maternal factors, Neonatal factors

\section{INTRODUCTION}

LBW is defined as a birth weight of less than 2500 gm (up to and including $2499 \mathrm{gm}$ ), as per world health organization (WHO). ${ }^{1}$ This definition of LBW was agreed upon in 1976 at $29^{\text {th }}$ world health assembly. LBW has been further subcategorized as very low birth weight (VLBW $<1500$ gm) and extremely LBW $<1000$ gm. ${ }^{1}$ Globally it is estimated that $15-20 \%$ of all births, or $>20$ million new births annually, are LBW infants. The incidence varies from 6\% in East Asia and Pacific to $28 \%$ in South Asia. ${ }^{2}$ Up to half of all LBW infants are born in South Asia. ${ }^{3}$ In India, $27 \%$ of newborn babies are low birth weight and is the main reason for infant mortality. ${ }^{4}$
Low birth weight is not only a public health indicator of maternal health, nutrition, access to health care services and poverty, but also an indicator of fetal-neonatal survival, healthy growth and development. These babies have 20 times greater risk of dying as compared to normal weight babies. $^{5}$ They also have long term neurologic disability, impaired language development and academic achievement and increased risk of chronic diseases like cardiovascular disease, diabetes. ${ }^{6}$

LBW is a result of either baby being born preterm (less than 37 completed weeks), intra-uterine growth restriction or both. The underlying causes of both fetal growth restriction as well as preterm delivery are multi-factorial. In general, the causes are an interaction between maternal, 
fetal and placental factors, with a common final pathway of insufficient utero-placental perfusion. Preterm birth may be spontaneous or medically induced. In developing countries like India, the majority of causes of LBW are intra-uterine growth restriction, only $6.7 \%$ are born preterm $^{7}$

The objective of our study was to find the various factorssocial, demographic, obstetric and fetal-neonatal characteristics-associated with these mothers who delivered low birth weight babies in our hospital.

\section{METHODS}

This observational study was conducted in the obstetrics and gynecology department of Bhaskar medical college and hospital, Moinabad, Hyderabad, Telangana, a rural tertiary care hospital from January 2016 to June 2017. All singleton pregnant women who delivered LBW babies at our hospital were included, and all those who had twins or still-births were excluded from our study. The sample size was calculated to be 131 , assuming a frequency of $27 \%$ with $95 \%$ confidence level and relative precision of $10 \%$. Our study sample comprised of 140 puerperal women who delivered low birth weight babies of less than $2500 \mathrm{gm}$ in our hospital.

Clearance was taken from institutional ethics committee. The study population was explained about the objectives of the study and informed consent was obtained. As per a pre-designed structured questionnaire, the mothers were interviewed about socio-demographic, obstetric, medical histories and all the records of clinical papers from early pregnancy till delivery were reviewed. All information about delivery and newborn baby were collected from the delivery notes, baby case sheets. Various characteristics of socio-demographic, obstetric (ante-natal and intra-natal) and anthropometric parameters were collected.

\section{Statistical analysis}

The data was entered in Microsoft excel and analysed with the help of SPSS version 16. Results were expressed as percentages in tables and as figures.

\section{RESULTS}

A total of 140 LBW new born babies and their mothers were included in the study (Table 1).

Table 1: Socio-demographic and obstetric characteristics of study population, $(n=140)$.

\begin{tabular}{|c|c|c|c|}
\hline Parameter & Categories & Frequency & Percentage $(\%)$ \\
\hline \multirow{4}{*}{ Age (years) } & $<20$ & 19 & 13.57 \\
\hline & $20-25$ & 105 & 75.0 \\
\hline & $26-30$ & 11 & 7.86 \\
\hline & $31-35$ & 05 & 3.57 \\
\hline \multirow{4}{*}{ Educational status } & Illiterate & 14 & 10.0 \\
\hline & Up to $7^{\text {th }}$ & 23 & 16.43 \\
\hline & $10^{\text {th }}-12^{\text {th }}$ & 88 & 62.86 \\
\hline & Graduate & 15 & 10.71 \\
\hline \multirow{3}{*}{ Working status } & Home makers & 116 & 82.86 \\
\hline & Students & 02 & 1.43 \\
\hline & Working & 22 & 15.71 \\
\hline \multirow{2}{*}{ Type of diet } & Vegetarian & 12 & 8.57 \\
\hline & Mixed & 128 & 91.43 \\
\hline \multirow{3}{*}{ Smoking } & Active & 02 & 1.43 \\
\hline & Passive & 58 & 41.43 \\
\hline & No & 80 & 57.14 \\
\hline Alcohol & Toddy & 04 & 2.86 \\
\hline \multirow{3}{*}{ Pre-pregnant weight $(\mathrm{n}=96)(\mathrm{kg})$} & $<45$ & 23 & 23.97 \\
\hline & $45-50$ & 17 & 17.70 \\
\hline & $>50$ & 56 & 58.33 \\
\hline \multirow{3}{*}{ Parity status } & Primipara & 83 & 59.28 \\
\hline & Para-2 & 42 & 30.0 \\
\hline & Para-3 & 15 & 10.72 \\
\hline \multirow{3}{*}{ Antenatal visits (number) } & No visit & 01 & 0.72 \\
\hline & Less than 4 & 06 & 4.28 \\
\hline & 4 or more & 133 & 95.0 \\
\hline \multirow{2}{*}{ Rest during ante-natal period } & 2 hours average & 118 & 84.28 \\
\hline & No rest taken & 22 & 15.72 \\
\hline \multirow{2}{*}{ Nutritional supplements } & Taken & 118 & 84.28 \\
\hline & Not taken & 22 & 15.72 \\
\hline
\end{tabular}




\begin{tabular}{|c|c|c|c|}
\hline Parameter & Categories & Frequency & Percentage (\%) \\
\hline \multirow{2}{*}{ Inter-pregnancy interval $(n=57)$ (Years) } & $>2$ & 44 & 77.2 \\
\hline & $<2$ & 13 & 22.8 \\
\hline \multirow{3}{*}{ Gestational age at delivery (weeks) } & $<34$ & 04 & 2.85 \\
\hline & $34-36+6$ & 45 & 32.14 \\
\hline & $>37$ & 91 & 65.0 \\
\hline \multirow{3}{*}{ Mode of delivery } & Vaginal & 75 & 53.57 \\
\hline & Instrumental & 05 & 3.57 \\
\hline & LSCS & 60 & 42.86 \\
\hline \multirow{3}{*}{ Weight of newborn (kg) } & $<1.5$ & 03 & 2.14 \\
\hline & $1.5-2.0$ & 25 & 17.86 \\
\hline & $2.1-2.5$ & 112 & 80.0 \\
\hline \multirow{2}{*}{$5 \min$ APGAR (n=139) } & 7 or More & 133 & 95.72 \\
\hline & 6 or less & 06 & 4.28 \\
\hline \multirow{2}{*}{ NICU admission ( $n=139)$} & Not needed & 103 & 74.1 \\
\hline & Needed & 36 & 25.9 \\
\hline \multirow{3}{*}{ Why NICU admission $(n=36)$} & RDS & 29 & 81.0 \\
\hline & Infection & 02 & 5.5 \\
\hline & Jaundice & 05 & 13.5 \\
\hline \multirow{2}{*}{ Neonatal outcome } & Survival & 139 & 99.28 \\
\hline & Death & 01 & 0.72 \\
\hline \multirow{3}{*}{$\begin{array}{l}\text { Weight gain during pregnancy }(\mathrm{n}=96) \\
(\mathrm{kg})\end{array}$} & $<6$ & 43 & 44.79 \\
\hline & $6-12$ & 44 & 45.83 \\
\hline & $>12$ & 09 & 9.38 \\
\hline \multirow{2}{*}{ Weight at delivery $(n=119)$} & $<50$ & 48 & 40.3 \\
\hline & $>50$ & 71 & 59.7 \\
\hline
\end{tabular}

Most of the mothers of these LBW babies (75\%) were in the age-group of 26-30 years and $62.8 \%$ had at least 10-12 years of schooling. $82.8 \%$ of these mothers were home makers. Most had a mixed diet $(91 \%)$. Active smoking was seen in only two women, $57 \%$ had no exposure to smoking. $41 \%$ of these women had passive smoking, either as wood being used for cooking or husbands habituated to smoking. Toddy (locally prepared alcohol) was taken by some women at home as it was supposed to be beneficial to fetal growth.

Three babies had birth weight $<1500 \mathrm{gm}$. All these 3 mothers had hypertension-1 mother had imminent eclampsia features at 33 weeks, the $2^{\text {nd }}$ mother was unbooked with IUGR and bicornuate uterus, both babies shifted to level $3^{\text {rd }}$ NICU facility and had good neonatal outcome. The $3^{\text {rd }}$ mother at 7 months of pregnancy came with eclampsia in labour, delivered within a few minutes a deeply asphyxiated baby of 800 gm which could not be revived.

Six of these babies had a low 5 min APGAR score- 2 of them recovered immediately, 1 baby was admitted in our NICU, 2 were shifted for level III NICU care, one was deeply asphyxiated, could not be revived.

Of all these babies, 36 needed admissions into NICU. 2 for infection (one of them had RDS too), 5 for phototherapy and 29 for RDS. 20 of these 20/29 RDS cases were managed at our hospital and another 9 were shifted to level
III NICU facility. Information about the transferred babies was gathered over phone and all these babies were said to be in good health.

Only one baby delivered at 7 months to a mother with eclampsia in late labour with $800 \mathrm{gm}$ at birth with birth asphyxia which could not be revived.

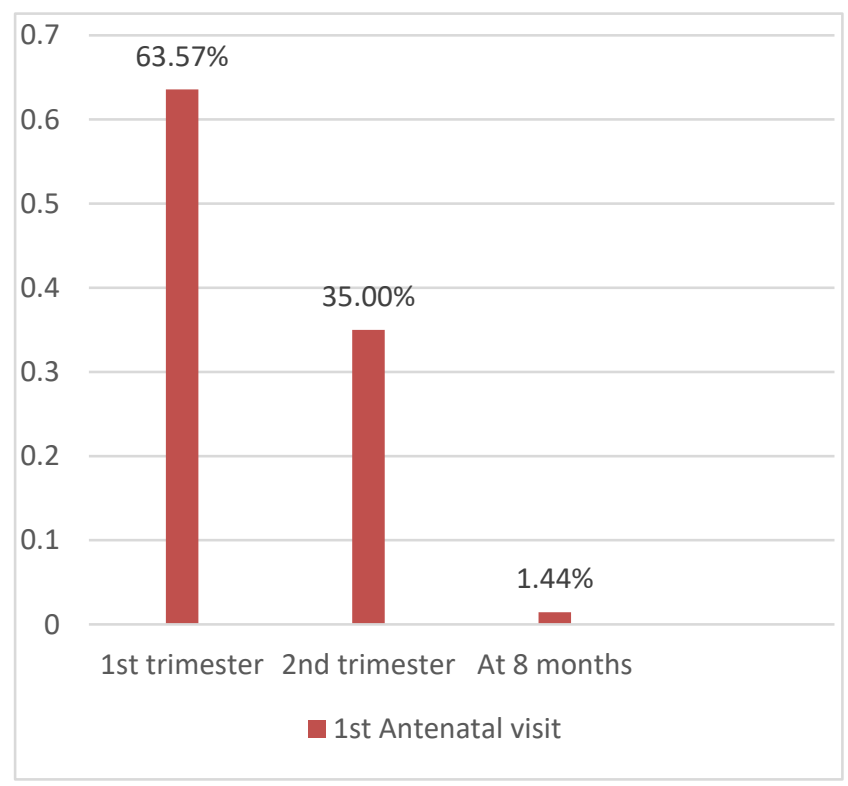

Figure 1: Distribution of mothers with respect to their $1^{\text {st }}$ ante-natal visit. 


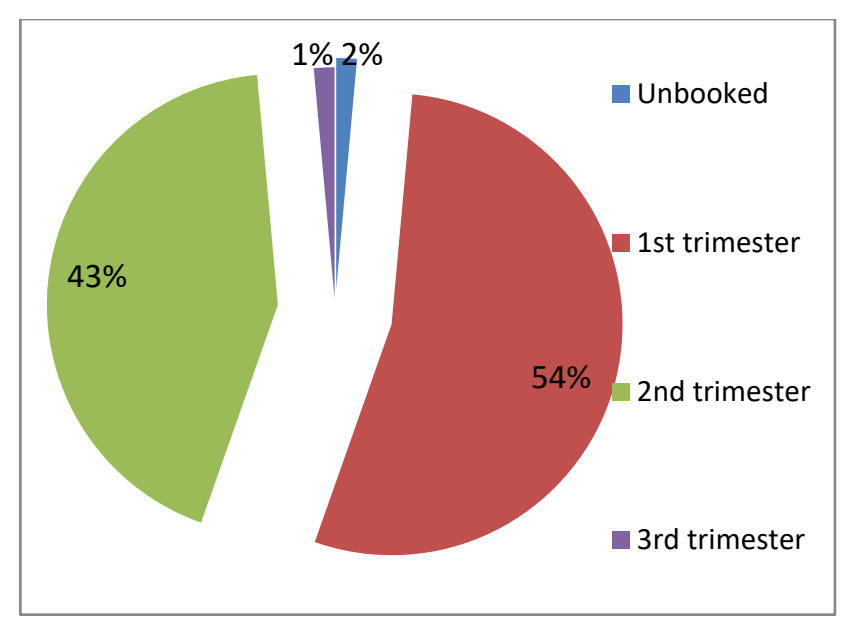

Figure 2: Distribution of mothers depending upon the time when the $1^{\text {st }}$ USG was done.

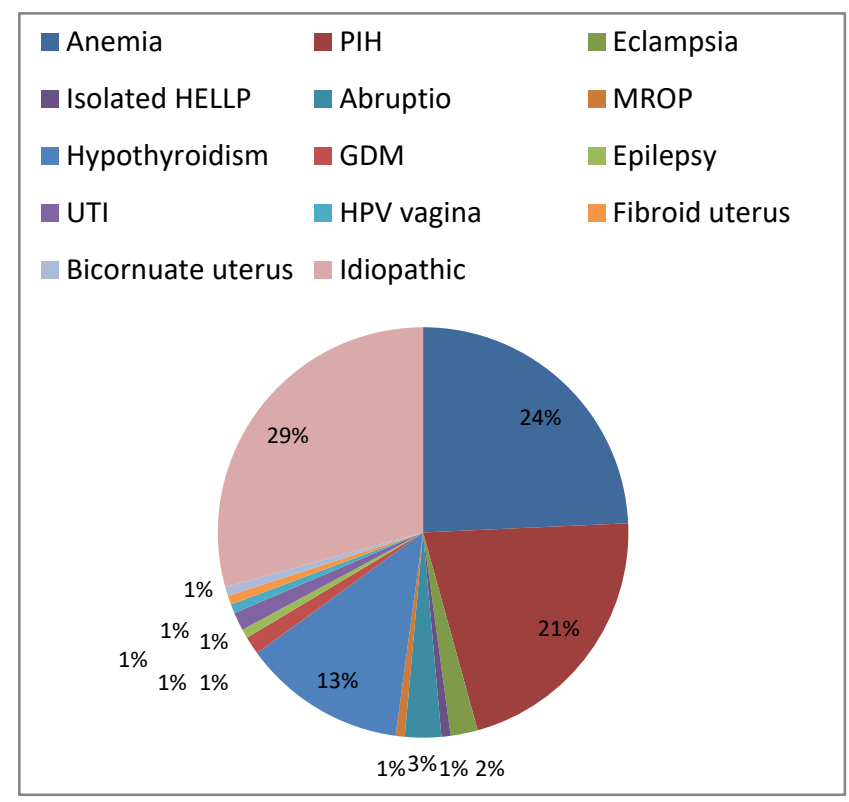

Figure 3: Distribution of mothers as per pregnancy related disorders.

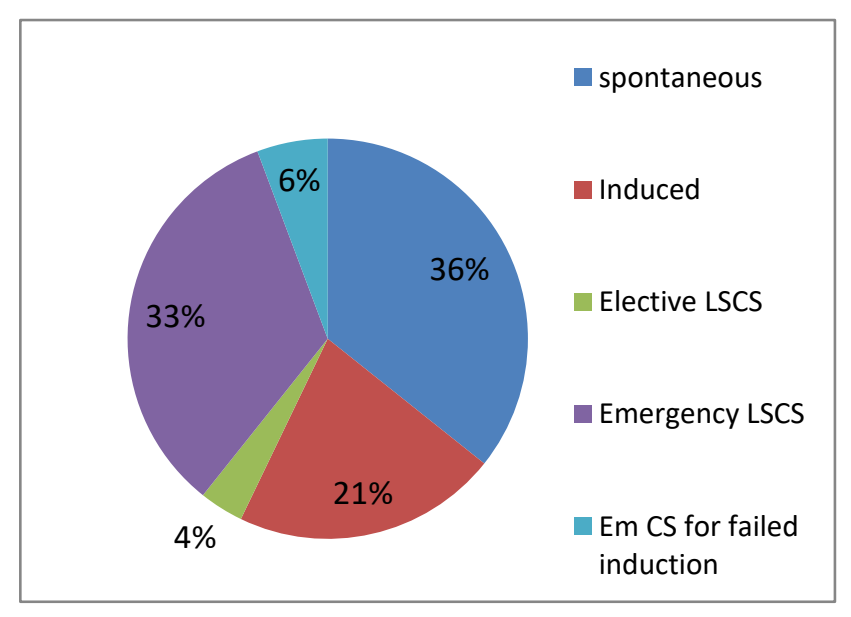

Figure 4: Mode of onset of labour and mode of delivery.

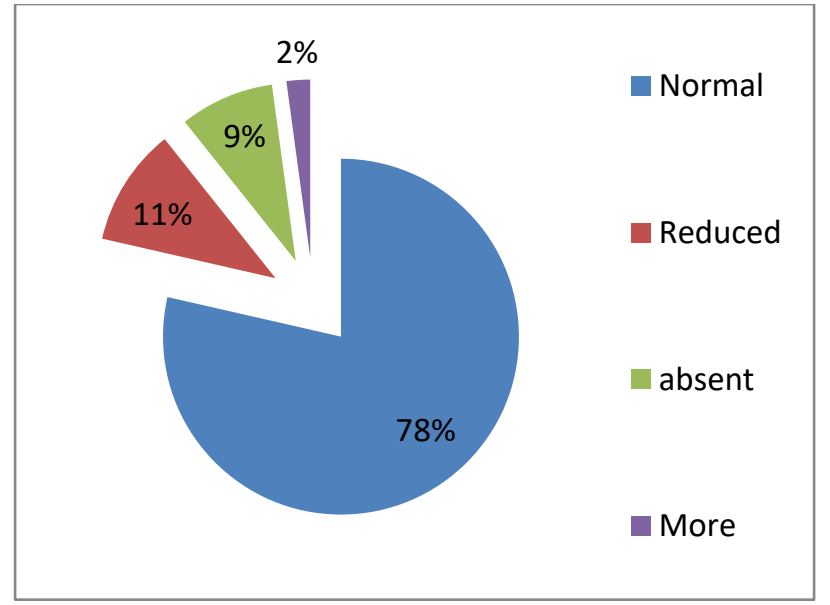

Figure 5: Amount of amniotic fluid.

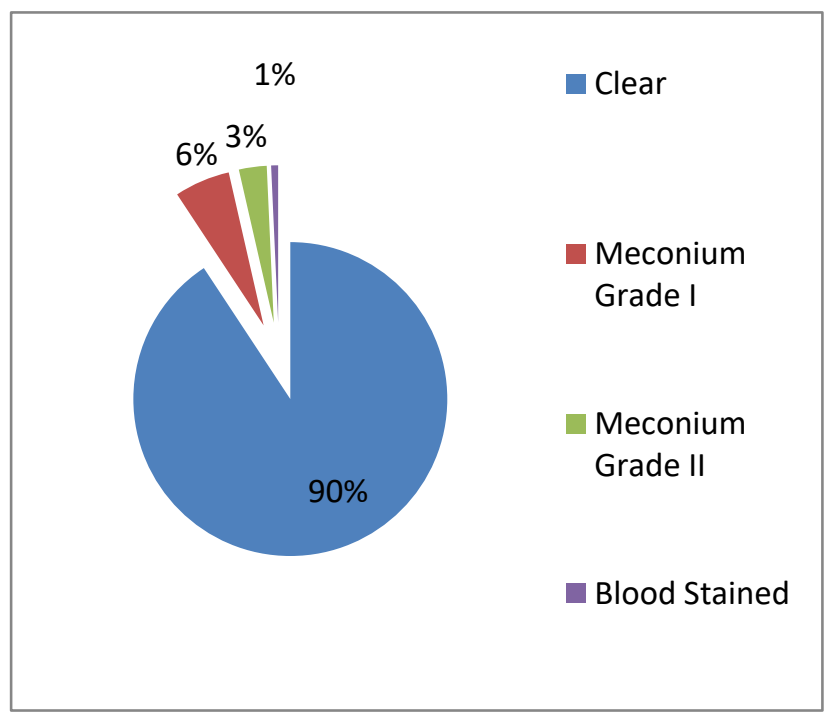

Figure 6: Color of amniotic fluid.

The $78.58 \%$ (130 of these 140 women) had at least 3 ultrasonographic evaluations during the pregnancy, 2 were un-booked, 28 had less than 3 USG examination. One patient had it 10 times during the said pregnancy and 3 had for 7 times each (Figure 2).

Anemia was seen in 34 patients, 3 had mild anemia and 31 had moderate anemia. 4 of the moderate anemia group had their anemia corrected by the time of delivery and 2 had their $\mathrm{Hb}$ levels rise to mild anemia category. Of the 34 mothers with hypertensive disorders of pregnancy, 3 had eclampsia, 2 had imminent eclampsia. 4 cases had Abruptio placentae-only one had blood-stained amniotic fluid and 3 had grade 0.18 of these mothers had hypothyroidism (Figure 3 ).

The $36 \%$ of these mothers had spontaneous vaginal delivery. $27 \%$ were induced and most delivered vaginally and some needed emergency LSCS. Overall figures for vaginal delivery were $57 \% \quad(4 \%$ were instrumental 
deliveries with the aid of forceps or ventouse). $43 \%$ delivered by LSCS (Figure 4).

In $6 / 10$ of these cases which had minimal or almost absent amniotic fluid, delivery was by LSCS, only 2 had RDS with NICU admission, but overall neonatal outcome was good. Only 1 baby had a birth weight of $1.3 \mathrm{~kg}$, all others had weight more than $2.1 \mathrm{~kg}$ and 1 baby had 1 loop of cord around the neck (Figure 5).

The 4 mothers showed features of abruptio placentae-only one had blood in the amniotic fluid, all the other 3 were grade 0 and diagnosed on examination of placenta after delivery (Figure 6).

Table 2: Meconium staining and neonatal outcome, $(n=10)$.

\begin{tabular}{|lllllll|}
\hline Consistency & $\begin{array}{l}\text { Liquor } \\
\text { amount }\end{array}$ & Delivery mode & Cord loop & RDS & $\begin{array}{l}\text { NICU } \\
\text { Admission }\end{array}$ & $\begin{array}{l}\text { Birth weight } \\
(\mathbf{k g})\end{array}$ \\
\hline Thin & Less & VD & 3 loops & Moderate & $\begin{array}{l}\text { Yes level 3 } \\
\text { NICU }\end{array}$ & 2.3 \\
\hline Thin & Normal & LSCS & 3 loops & No & No & 2.45 \\
\hline Thick & Less & VD & No & No & No & 2.4 \\
\hline Thick & Less & Forceps & No & Mild & No & 2.3 \\
Thin & Normal & VD & No & No & No & 2.3 \\
\hline Thin & Normal & LSCS & No & No & No & 2.25 \\
\hline Thin & Less & LSCS & No & Mild & No & 2.3 \\
\hline Thick & Less & LSCS & No & No & No & 2.25 \\
\hline Thick & Less & LSCS & No & No & No & 2.25 \\
\hline Thick & less & LSCS & No & Moderate & Yes & 2.2 \\
\hline
\end{tabular}

Table 3: Umbilical cord loop and neonatal outcome $(n=15)$.

\begin{tabular}{|lllllll|}
\hline No of loops & Delivery mode & Liquor colour & Liquor amount & RDS & NICU admission & Birth weight \\
\hline Single loop & VD & Normal & Normal & No & No & 2.4 \\
\hline Single loop & VD & Normal & Normal & No & No & 2.4 \\
\hline Single loop & VD & Normal & Scanty & No & No & 2.1 \\
\hline Single loop & $\begin{array}{l}\text { Breech VD } \\
\text { preterm }\end{array}$ & Normal & Normal & Moderate & Yes & 2.0 \\
\hline Single loop & VD & Normal & Normal & No & No & 2.4 \\
\hline Single loop & LSCS & Normal & Normal & No & No & 2.0 \\
\hline Single loop & VD & Normal & Normal & Mild & Yes & 2.0 \\
\hline Single loop & Forceps & Normal & Normal & No & No & 2.4 \\
\hline Single loop & LSCS & Normal & Normal & Mild & Yes & 2.0 \\
\hline Single loop & LSCS & Normal & Normal & No & No & 2.25 \\
\hline Single loop & Vacuum & Normal & Normal & No & No & 2.25 \\
\hline Single loop & VD & Normal & Normal & No & No & 2.25 \\
\hline 2 loops & LSCS & Normal & Normal & No & No & 2.0 \\
\hline 3 loops & LSCS & Normal & Normal & No & No & 1.8 \\
\hline 3 loops & LSCS & Normal & Normal & No & Yes phototherapy) & 2.45 \\
\hline
\end{tabular}

The 5 each had grade I and grade II meconium staining of the amniotic fluid. Irrespective of the grade of meconium, 4 had vaginal delivery, 2 had moderate RDS and NICU admission. One baby after vaginal delivery with thin meconium and normal amount of amniotic fluid had moderate RDS and had to be shifted for level III NICU care (baby had 3 loops of umbilical cord around its neck) (Table 2).

The 9/12 of these LBW babies with one loop of cord around the neck delivered vaginally and only $3 / 12$ of these had mild to moderate RDS which was easily managed at our hospital. This correlates with studies that umbilical cord loop around neck is not an indication for caesarean delivery. All 3 babies with two or more than 2 loops around the neck had LSCS for other obstetric indications (Table 3).

\section{DISCUSSION}

This study was done to find out the various factors associated with the birth of LBW babies. Hospital provides health care at very nominal rates for investigations and safe confinement, this appears to be one of the factors for highrisk pregnancy care and delivery being opted by pregnant women in area and high compliance to antenatal visits, investigation protocols and treatment.

Pregnancy at a younger age, $<20$ years or $>30$ years have been considered a risk factor for LBW babies. Negi et al. ${ }^{8}$ 
in their study in 2006 found that women in this age-group had twice the incidence of LBW babies as also Rajashree et al in 2015. ${ }^{9}$ NFHS-4 of $2015-16^{10}$ showed that in Telangana, $26 \%$ of women have at least one child by 19 years of age. In our study of the mothers with LBW babies, only $13.5 \%$ (19 out 140) were of this age-group.

Studies by Joshi et al and Rajashree et al have shown that up to $44-48 \%$ of women with LBW babies were working women. ${ }^{9,11}$ In our study sample, most (82.86\%) were home-makers, only $15.72 \%$ were working women. These were also the women who could not take adequate afternoon rest nor took additional supplements due to socio-economic reasons.

Table 4: Comparison of ante natal care parameters.

\begin{tabular}{|lll|}
\hline Parameter & $\begin{array}{l}\text { NFHS 4 } \\
(\%)\end{array}$ & $\begin{array}{l}\text { Present study } \\
(\%)\end{array}$ \\
\hline $\begin{array}{l}\text { Antenatal care in } \\
\text { preceding 5 years }\end{array}$ & 86 & 98.56 \\
\hline $\begin{array}{l}\text { +4 or more ante-natal } \\
\text { visits }\end{array}$ & 75 & 95 \\
\hline Ultrasound done & 91 & 98.44 \\
\hline $\begin{array}{l}\text { Iron and folic acid } \\
\text { supplements }\end{array}$ & 91 & 98.56 \\
\hline Severe Anaemia & 3 & Nil \\
\hline
\end{tabular}

Also $78.6 \%$ of our patients had at least 3 ultrasound tests during the pregnancy, as per the recommended FOGSI antenatal protocols. This higher accessing of health care services by our study population $(98.56 \%)$ than our state average levels can be attributed to 3 factors-provision of free antenatal services at our hospital, easy accessibility to tertiary care services and higher education levels of our study subjects $(73.57 \%$ had more than 10 years of schooling as compared to the state average of $45.5 \%$ female literacy). It can be inferred from the above that the governments in different states should endeavor to make quality antenatal services easily and freely available to pregnant women (Table 4).

Iron and folic acid supplements were taken by all of these women (98.56\%), either at our hospital or those provided free by local Anganwadi workers of primary health centre (excepting 2 who were un-booked). NFHS-4 reported that in state IFA supplements were received by $91 \%$ pregnant women during last pregnancy; but only 53\% consumed them for recommended 100 days or more (Table 4).

Nutritional supplements like proteins and vitamins, and afternoon rest of 2 hours were taken by 118 (84.28\%) of these women during the ante-natal period. But 28 $(15.72 \%)$ of them could not take rest as they were all working as laborers-daily wagers or farmers.

Maternal anemia has been associated with birth of LBW babies as reported in various studies. In their studies of anemia in mothers of LBW deliveries, Bassetty et al in Assam in 2017 reported 66.5\%, Gagan et al and Sain et al from North India reported $47 \%$, Rajashree et al (South India) reported 53\% and Prah et al from Ghana in 2016 reported $58 \%$ anemia incidence. ${ }^{9,12-15}$ Our study showed a significantly lower incidence of $24.28 \%$ anemia.

The probable explanation for the lower incidence of anaemia among our pregnant women may be that most of our patients were home-makers, had mixed diet which included chicken, fish etc, had ANC visits from $1^{\text {st }}$ Trimester allowing enough time for anemia correction (as compared to the study by Bassetty et al where the women were tea estate workers, had infrequent ANCs and infrequent ultrasonography). Actually 4/31 of our moderately anemic women had their $\mathrm{Hb}$ levels rising to normal values by the time of delivery and another 2 had it raised to levels of mild severity. None of our patients had severe anemia though NFHS-4 reported 3\% incidence of severe anemia in pregnant women.

Similarly, Bassetty et al reported a high, $58.5 \%$ incidence of hypertensive disorders of pregnancy in their study population; in study $24.28 \%$ (34 patients) had hypertensive disorders of pregnancy. The 18 of our mothers with LBW babies $(12.86 \%)$ had hypothyroidism. The latter is in contrast to a study by us in our hospital in 2015 which had reported a higher incidence of hypothyroidism of $19.14 \%$ (260 out of 1340 pregnant women). ${ }^{16}$

A short inter-delivery interval of less than 2 years has been said to cause LBW due to poorer nutritional status and breast feeding. Rajashree et al reported a high incidence of 73.35 of their study population having a short interdelivery interval and Dubey et al had this incidence of $34 \% .^{9,17}$ In our study only $22.81 \%$ of the study group had less than 2 years of inter-delivery interval. Our lower incidence shows that accessing antenatal care services from early in gestation, regular antenatal checkups, proper diet, nutritional support and adequate rest are useful to overcome the adverse effect of short inter-delivery interval on fetal weight, reported by most of the studies.

WHO has said that the most important predictor of infant mortality is birth weight of newborn babies. As only 3 babies had a birth-weight of less than $1.5 \mathrm{~kg}$, the overall neonatal outcome in our study had a significantly better result as compared to other studies.

Coffey, nobel laureate for economics in her article in proceedings of the national academy of sciences of the U.S.A. published online 2015 March stated that despite being wealthier, Indian children are significantly shorter and smaller than African children. ${ }^{18}$ These differences begin very early in life, suggesting that they may in part reflect differences in maternal health. This difference in pre-pregnancy weight of less than $50 \mathrm{~kg}$ in Indian women (42.2\% vs $16.5 \%$ in sub-Saharan Africa) may partly be explained by the fact that child-bearing is concentrated in the narrow age-range in which Indian women are likely to be underweight (early marriage and child-bearing). Poor maternal health among Indian women is of global 
significance because India is home to $1 / 5^{\text {th }}$ of the world's births. Further, because weight-gain during pregnancy is low, averaging about $7 \mathrm{~kg}$ for a full-term pregnancy in both regions, the average woman in India ends pregnancy weighing less than the average women in sub-Saharan Africa begins pregnancy.

This correlated with our study- $41.67 \%$ of our study sample had pre-pregnancy weight of $<50 \mathrm{~kg}$ and $91 \%$ of these had a weight-gain of less than $12 \mathrm{~kg}$ during the pregnancy. Also $40.3 \%$ in our study had a weight of less than $50 \mathrm{~kg}$ at the time of delivery, almost similar to a study by Gebremedhin et al in Ethiopia in 2015 (36.7\%). ${ }^{19}$

Limitation or drawback of this study is it's not being a case control study hence statistical significance of various factors could not be assessed (though sample size was a good 140 LBW babies).

\section{CONCLUSION}

For prevention of birth of LBW babies, provision of free and quality antenatal care services by the government will make all pregnant women access such care. Improving education levels of women, and health education to adolescents to achieve optimal pre-pregnancy nutritional health by way of weight and anemia correction before embarking upon a pregnancy will also help.

\section{ACKNOWLEDGMENTS}

Author would like to thanks the clinicians of our departments of obstetrics and gynecology and pediatrics and to the subjects of our study for enabling us to prepare this paper.

\section{Funding: No funding sources}

Conflict of interest: None declared

Ethical approval: The study was approved by the Institutional Ethics Committee

\section{REFERENCES}

1. Organization WHO International statistical classification of diseases and related health problems, tenth revision, $2^{\text {nd }}$ edition. World Health Organization. 2004.

2. WHO Global nutrition targets: Low Birth Weight Policy Brief Geneva. WHO. 2004.

3. Lawn JE, Cousens S, Zupan J. 4 million neonatal deaths: when? where? why? Lancet. 2005;365(9462):891-900.

4. UNICEF. State of World's Children. New York, NY: UNICEF. 2009.

5. Kramer MS. Determinants of Low Birth Weight: methodological assessment and meta-analysis. Bull World Health Organization. 1987;65(5):663-737.

6. Zerbeto AB, Cortelo FM, Elio Filho BC. Association between Gestational Age and Birth Weight on the language development of Brazilian children: a systematic review. J de Pediatr. 2015;91(4);326-32.

7. Muthayya S. Maternal nutrition and low birth weightwhat is really important? Ind J Medical Research. 2009; 130:600-8.

8. Negi KS, Kandapal SD, Kukreti M. Epidemiological factors affecting Low Birth Weight. JK Science. 2006;8(1):31-4.

9. Rajashree K, Prashanth HL, Revathy R. Study on the factors associated with low birth weight among newborns delivered in a tertiary care hospital, Shimoga, Karnataka. Int J Med Sci Public Health. 2015;4:1287-90.

10. National Family Health Survey (NFHS)-4. 2015-16.

11. Joshi HS, Srivastava PC, Agnihotri AK, Joshi MC, Chandra S, Mahajan V. Risk factors for low-birthweight babies and its medico-legal significance. J Indian Acad Forensic Med. 2014;32(3).

12. Bassetty KC, Phukan P, Ahmed RD, Borah R. Outcomes of neonates in pregnancies with IUGR in Developing countries: A cross sectional study over a period of 6 months. Gynecol Obstet (Sunnyvale). 2017;7(4):1000434.

13. Gagan A, Satraj A, Kapil G, Kumar V, Parul G. Maternal risk factors associated with low-birth-weight neonates in tertiary care hospital, Northern India. J Community Med Health Edu. 2012;2:177.

14. Sain S, Mukhopadhyay P, Saha TK, Chattopadhyay A, Dey I, Mandal NK. Effect of maternal factors on LBW in a Medical college of Kolkata. J comprehensive Health. 2014;2:2.

15. Prah J, Ameyaw EO, Afoakwah R, Kudom A. Factors affecting birth weight in Cape Coast, Ghana. Int $\mathbf{J}$ Reprod Contracept Obstet Gynecol. 2016;5(5):15369.

16. Murty NVR, Uma B, Rao JM, Sampurna K, Vasantha K, Vijayalakshmi G. High prevalence of Sub-clinical Hypothyroidism in pregnant women in South India. Intl J Reprod Contracept Obstet Gynecol. 2015;4(2):453-6.

17. Dubey M, Rout AJ, Ram R, Saha JB, Chakrabarty M, Biswas N. Relationship between low birth weight of babies and antenatal care of mothers: A cross sectional study at a tertiary care hospital of Kishanganj, Bihar. Global J Med Public Health. 2015;4:6.

18. Coffey D. Pre-pregnancy body mass and weight gain during pregnancy in India and sub-Saharan Africa. Pro Natl Acad Sci USA. 2015;112(11):3302-7.

19. Gebremedhin M, Ambaw F, Admassu E, Berhane H. Maternal associated factors of low birth weight: A hospital based cross-sectional mixed study in Tigray, Northern Ethiopia. BMC Pregnancy Childbirth. 2015; 15:222.

Cite this article as: Nabhi MVR, Ramajyoti S, Vydehi B, Vasantha K, Vijayalakshmi G. Low birth weight: an observational study of maternal and neonatal factors in a rural tertiary care hospital, Telangana, India. Int J Reprod Contracept Obstet Gynecol 2021;10:2799-805. 